${ }^{1}$ Herminio Ometto University Center, School of Dentistry, Araras, Sao Paulo, Brazil.

${ }^{2}$ Department of Post-graduation in Implantology, University of Santo Amaro, School of Dentistry. São Paulo, SP, Brazil.
Corresponding author: Renata Siqueira Scatolin Herminio Ometto University Center, School of Dentistry, Araras-SP, Brazil Dr. Maximiliano Baruto Avenue, 500 - University Garden, Araras - SP, 13607-339.

Fone - Fax: +55 (19) 3543-1400 e-mail: re_scatolin@hotmail.com

Received: April 17, 2020

Accepted: September 23, 2020

\section{Effect of violet led associated with low-concentration hydrogen peroxide on enamel surface roughness}

\author{
Natalia Eugenio', Innocenzo Scandiffio', Marcia \\ Hiromi Tanaka², Ana Luisa Botta Martins de Oliveira', \\ Renata Siqueira Scatolin ${ }^{1, *}$ (D)
}

Aim: The present study aimed to assess in vitro the effect of violet LED in tooth bleaching techniques associated or not with low-concentration hydrogen peroxide gel on enamel surface roughness. Methods: Fifty-two enamel fragments of bovine teeth were flattened and polished $(4 \times 4 \times 3 \mathrm{~mm})$ and divided into four groups according to bleaching treatment: VL- Violet LED; HP- 7.5\% hydrogen peroxide; HP+VL- 7.5\% hydrogen peroxide + violet LED; C- No bleaching (control). Before the treatments, all specimens were immersed in $20 \mathrm{~mL}$ of black tea for six days, changing solutions every $24 \mathrm{~h}$ to simulate the staining of specimens. Forty fragments were used to analyze surface roughness $(n=10)$ and 12 fragments were used for the morphological analysis (SEM) $(n=3)$. Results: The data were submitted to one-way ANOVA and a post-hoc Tukey test. The lower roughness values was observed for the group that did not receive bleaching treatment (C), differing significantly only from the group bleached with $7.5 \%$ hydrogen peroxide + violet LED $(\mathrm{HP}+\mathrm{VL})(\mathrm{p}=0.0077)$. The remaining groups did not show significant differences in roughness values ( $p>0.05)$. The scanning electron microscopy analysis showed irregularities on the enamel surface regardless of the treatment received. Conclusion: The results showed that bleaching treatments with violet LED associated with low-concentration hydrogen peroxide gels (7.5\%) increase the surface roughness of tooth enamel.

Keywords: Dental enamel. Hydrogen peroxide. Tooth bleaching 


\section{Introduction}

The most common bleaching process is the application of carbamide peroxide or hydrogen peroxide gel on tooth enamel ${ }^{1,2}$, using techniques performed in-office or at home by the patient. In the initial phases, after the application of gels, a chemical reaction of oxide reduction occurs, in which the pigmented carbon molecules are broken and converted into smaller molecules with a lighter color, promoting the bleaching effect ${ }^{3}$. Light sources are often used in association with gels to accelerate the decomposition of peroxides, but they may also increase the temperature of the tooth structure depending on the light source used ${ }^{4}$.

These tooth bleaching techniques show to be effective as a color change, but in many cases, it can cause tooth sensitivity ${ }^{2}$. They are also seen in the literature some unwanted effects on the enamel structure related to peroxide gels and some associated light sources, among which are roughness increase, hardness decrease, and surface morphology changes ${ }^{5,6}$. Such changes may be harmful to patients because of the increase in enamel porosity, facilitating the adhesion of microorganisms ${ }^{7}$.

In this light, the search for procedures that are less harmful to the dental structure has also led to the development of different tooth bleaching products and techniques ${ }^{8}$. Violet LED devices can supposedly fragment the pigmented molecules through a physical medium, in which the absorption peak of these molecules matches the violet light emission range (405-410 nm), transforming them into smaller and less pigmented molecules ${ }^{9}$ that can bleach even without the gel association, decreasing the risk of the harmful effects of bleaching related to peroxide, providing safety and comfort for patients ${ }^{10,11}$.

Thus, this study aimed to assess in vitro the enamel surface roughness after tooth bleaching techniques using violet LED associated or not with low-concentration hydrogen peroxide gels, considering the literature is scarce of such information.

\section{Materials and methods}

\section{Experimental design}

Fifty-two fragments of bovine teeth were included, 40 of them were used for the surface roughness analysis $(n=10)$ and 12 fragments were used for the morphological analysis $(S E M)(n=3)$. The experimental groups were divided according to the bleaching procedure proposed: VL- violet LED; HP- 7.5\% hydrogen peroxide; HP+VL- 7.5\% hydrogen peroxide + violet LED; C- no bleaching (control). The outcome variables were subjected to surface roughness analysis (quantitative analysis) and scanning electron microscopy (qualitative analysis).

\section{Sample collection}

The sample collection included bovine teeth without cracks or hypoplastic stains. The crowns of the teeth were sectioned in the middle third with an electric precision cutter (Isomet 1000; Buehler, Lake Bluff, IL, USA) aided by a diamond disc, to obtain 40 fragments with dimensions of $4 \times 4 \times 3 \mathrm{~mm}$. 
The enamel surface was then flattened in a water-cooled rotary polisher (DP-9U2; Struers S/A, Copenhagen, Denmark) with \#600 and \#1200 abrasive files and polished with $0.3-\mu \mathrm{m}$ alumina paste and polishing felt. After polishing, the specimens were cleaned in ultrasound for five minutes.

\section{Staining of fragments}

For staining the enamel fragments, they were immersed individually in $20 \mathrm{~mL}$ of black tea (Leão Júnior S.A., Curitiba, Brazil) in the ratio of $1.6 \mathrm{~g}$ of black tea leaves to $100 \mathrm{ml}$ of distilled water for five minutes, with posterior filtration to remove the tea leaves ${ }^{12}$. This solution was replaced every $24 \mathrm{~h}$ for six days $8,12, \mathrm{pH} 5,1$ and room temperature $\left( \pm 22^{\circ} \mathrm{C}\right)$. At the end of the staining, the samples were washed with deionized water for one minute and dried with absorbent paper to receive the treatments.

\section{Bleaching of enamel fragments}

The applications and number of bleaching sessions were performed according to the manufacturer's instructions, to the following protocols:

VL- Bleached with violet LED (Bright Max Whitening, MMO, São Carlos, SP, Brazil): Seven sessions of 30 minutes were performed, in which the light was applied at $8 \mathrm{~mm}$ of distance from the tooth surface, 20 times for 60 seconds, and turned off between each application for 30 seconds. Each session had a 7-day interval in between.

HP- Bleached with 7.5\% hydrogen peroxide (Whiteness Class, FGM, Joinville, SC, Brazil): Fifteen $7.5 \%$ hydrogen peroxide gel applications were performed for one hour on a layer of 0.5 to $1 \mathrm{~mm}$ of thickness on the enamel surface. Each application had a 24-hour interval in between.

$\mathrm{HP}+\mathrm{VL}$ - Bleached with 7.5\% hydrogen peroxide (Whiteness HP Blue, FGM, Joinville, SC, Brazil) + violet LED (Bright Max Whitening, MMO, São Carlos, SP, Brazil): The 7.5\% hydrogen peroxide was applied on the surface of the fragments as described for group HP, added by the association of violet LED application as described for group VL. Three sessions were performed with a 7-day interval in between.

C- No bleaching (control): During the bleaching period of groups $V L, H P$ e HP+VL the specimens of group $\mathrm{C}$ remained in deionized water.

During the intervals of treatments, the samples were kept in relative humidity with deionized water in an oven at $37^{\circ} \mathrm{C}$.

\section{Surface roughness analysis}

The roughness of the specimens was analyzed with a digital roughness meter (model SJ 301, Mitutoyo Corporation Inc., Kanagawa, Japan). Roughness was assessed at two times: before and after the treatment with bleaching agents. The parameter for measuring roughness was Ra (average roughness) and the cut-off used was $0.25 \mathrm{~mm}$. The Ra values represents the arithmetic mean of the size of peaks and valleys found during surface scanning. 


\section{Scanning electron microscopy}

Three specimens from each group were put in distilled water in the ultrasound (10 minutes) and later they received dehydration in ascending levels of ethanol (Labsynth Ltda., Diadema, SP, Brazil): 25\% (20 min), 50\% (20 min), 75\% (20 min), 95\% (30 min), and $100 \%$ (60 min). As dehydration was concluded, the specimens were fixed in stubs and metalized with a layer of gold-palladium alloy in a vacuum metallization apparatus (SDC 050, Bal-Tec AG, FL9496, Balzers, Liechtenstein). The specimens were examined in a scanning electron microscope (Zeiss, EVO 50, Cambridge, England) for the qualitative analysis of the morphological change of enamel caused by the treatments. The area that most represented each group was photographed with (X3000) magnification.

\section{Statistical analysis}

After being tested for normality and homoscedasticity, using Shapiro-Wilk's and Levene's tests, respectively, the data were submitted to one-way ANOVA and a post-hoc Tukey test. For all tests, the significance level of $5 \%$ was considered. The data were analyzed using the GraphPad Prism (GraphPad Software, La Jolla, CA, USA) and JAMOVI (The jamovi project (2020). Jamovi. (version 1.2) retrieved from https://www.jamovi.org).

\section{Results}

Comparing the roughness values before and after the treatments, there was a significant increase in the roughness values for all groups, with no differences between them.

Lower roughness values for the group that did not receive bleaching treatment (C) was observed, differing significantly only from the group bleached with $7.5 \%$ hydrogen peroxide + violet $L E D(H P+V L)(p=0.0077)$. Among the remaining groups, there were no significant differences in roughness values $(p>0.05)$. (Table 1 )

Table 1. Mean $( \pm S D)$ of Ra values $(\mu \mathrm{m})$ of the specimens that were stained and later received bleaching treatments

\begin{tabular}{lccccc}
\hline Groups & $\begin{array}{c}\text { VL } \\
(\text { Violet LED })\end{array}$ & $\begin{array}{c}\text { HP } \\
(7.5 \% \text { hydrogen } \\
\text { peroxide })\end{array}$ & $\begin{array}{c}\text { HP+VL } \\
(7.5 \% \text { hydrogen } \\
\text { peroxide + violet LED })\end{array}$ & $\begin{array}{c}\text { C } \\
\text { (No bleaching) }\end{array}$ & p value \\
\hline Ra before $(\mu \mathrm{m})$ & $\begin{array}{c}0.0633 \\
( \pm 0.0212) \mathrm{Ab}\end{array}$ & $\begin{array}{c}0.0622 \\
( \pm 0.0210) \mathrm{Ab}\end{array}$ & $\begin{array}{c}0.0588 \\
( \pm 0.0226) \mathrm{Ab}\end{array}$ & $\begin{array}{c}0.0600 \\
( \pm 0.01187) \mathrm{Ab}\end{array}$ & 0.96 \\
\hline Ra after $(\mu \mathrm{m})$ & $\begin{array}{c}0.3778 \\
( \pm 0.2154) \mathrm{ABa}\end{array}$ & $\begin{array}{c}0.3378 \\
( \pm 0.1258) \mathrm{ABa}\end{array}$ & $\begin{array}{c}0.4422 \\
( \pm 0.1838) \mathrm{Aa}\end{array}$ & $\begin{array}{c}0.2433 \\
( \pm 0.0678) \mathrm{Ba}\end{array}$ & 0.0077 \\
\hline P value & 0.0022 & 0.0022 & 0.0003 & $<0.0001$ & \\
\hline
\end{tabular}

*Means followed by different uppercase letters indicate statistically significant difference between groups (lines) and different lowercase letters mean statistically significant difference between intragroups (collums).

The images obtained with scanning electron microscopy (Figure 1) showed irregularities on the enamel surface regardless of the bleaching treatment performed $(V L, H P$ e HP+VL). Changes in the enamel surface morphology are also present for the group that received only the process of staining with black tea and no bleaching (C). 

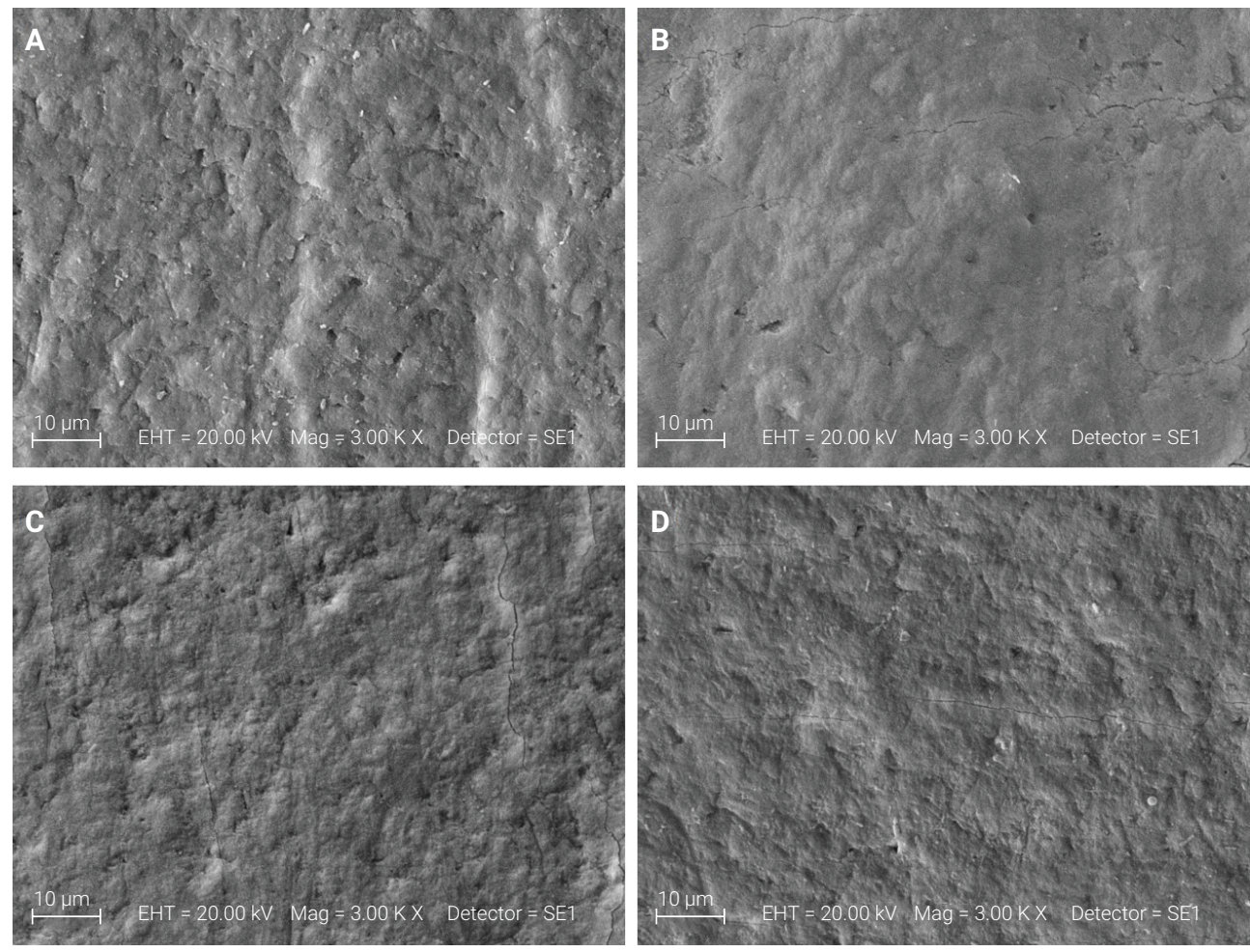

Figure 1: A. Violet LED; B. 7.5\% Hydrogen peroxide; C. 7.5\% Hydrogen peroxide + Violet LED; D. No bleaching

\section{Discussion}

The evaluation of the enamel changes after different bleaching techniques needs to be studied, because factors such a surface roughness can lead to the accumulation of biofilm with a consequent increase in the risk of developing caries injury and periodontal disease?.

In this study, all groups showed an increase in average surface roughness values (Ra) when compared to the initial surface roughness values. Even though group $\mathrm{C}$ received no treatment, it was subjected to staining with black tea as all the other groups, which would explain the increase in roughness values, considering this beverage shows an erosive potential ${ }^{13}$. Dental exposure to drinks with $\mathrm{pH}$ values below 5.5 , considered critical for the dissolution of enamel prisms, with long duration and the absence of intrinsic buffering systems of saliva, may have contributed to the changes in the enamel microstructure ${ }^{14}$. It can also be identified by the scanning electron microscopy images.

According to Kury et al. ${ }^{15}$ (2020), the bleaching treatment with violet LED (VL) showed similar enamel morphology to the untreated group (C), which shows the safety of its use for dental enamel. These similarities were also observed in this study. The roughness tests showed no significant differences between them too. When the violet LED was applied associated to the $7.5 \%$ hydrogen peroxide $(\mathrm{HP}+\mathrm{VL})$, the surface roughness increased when compared with untreated group $(C)$, but there was no difference in the roughness values when the treatments were applied alone. 
Ergin et al. ${ }^{16}$ (2018) observed an increased enamel roughness by associating 35\% hydrogen peroxide with different types of light (diode laser, Er:YAG laser, or blue LED). Light sources accelerate the bleaching procedure by heating the bleaching gels to increase the decomposition rate of oxygen to oxygen-free radicals and raise the release of stained molecules ${ }^{17}$. The free radicals produced during bleaching penetrate within the interprismatic regions and react with pigmented molecules and the organic matrix of the enamel, increasing the surface irregularity of this enamel ${ }^{18}$. The increased surface roughness after bleaching facilitates the staining of teeth and restorative materials by the adhesion of dye pigments and microorganisms ${ }^{19,20}$, which causes great concern to both professionals and patients.

Studies have shown that bleaching with hydrogen peroxide promotes structural changes in enamel, characterized by superficial depressions ${ }^{21,22}$, greater porosity ${ }^{21}$, exposure of enamel prisms ${ }^{21}$, increased surface roughness ${ }^{22}$, decreased hardness, and loss of mineral content ${ }^{23}$. These changes occur due to enamel demineralization and they may facilitate the accumulation of plaque ${ }^{24}$. The adverse effects of bleaching on enamel morphology depend on the concentration of hydrogen peroxide, its $\mathrm{pH}$, and exposure time 25 .

Despite the increased values of tooth enamel roughness observed in the bleaching technique with gel associated with the violet LED, it is difficult to affirm whether such changes are clinically reversible or not. This study was performed in vitro and perhaps the presence of saliva, fluorides, or other remineralizing solutions would have maintained a balance between the processes of demineralization and remineralization $^{26}$, minimizing the adverse effects of tooth bleaching ${ }^{19,27}$. Thus, in vivo studies are required to understand the effects of bleaching agents associated with a violet LED on tooth enamel.

\section{Acknowledgments}

The authors would like to thank the Institutional Scholarship Program for Scientific Initiation and Research Support for the scholarship awarded, and University of São Paulo, for authorization to use the equipments.

*Number of the approved protocol issued by the Ethics Institution Committee: 010/2019.

\section{References}

1. Monteiro RV, Monteiro S Jr, Caldeira de Andrada MA. Clinical evaluation of two in-office dental bleaching agents. Am J Dent. 2018 Oct;31(5):239-42.

2. Mounika A, Mandava J, Roopesh B, Karri G. Clinical evaluation of color change and tooth sensitivity with in-office and home bleaching treatments. Indian J Dent Res. 2018 Jul-Aug;29(4):423-7. doi: 10.4103/ijdr.IJDR_688_16.

3. Goldberg M, Grootveld M, Lynch E. Undesirable and adverse effects of tooth-whitening products: a review. Clin Oral Investig. 2010;14(1):1-10. doi: 10.1007/s00784-009-0302-4.

4. Luk K, Tam L, Hubert M. Effect of light energy on peroxide tooth bleaching. J Am Dent Assoc. 2004;135(2):194-229. doi: 10.14219/jada.archive.2004.0151. 
5. Klaric E, Rakic M, Sever I, Milat O, Par M, Tarle Z. Enamel and Dentin Microhardness and Chemical Composition After Experimental Light-activated Bleaching. Oper Dent. 2015;40(4):E132-41. doi: 10.2341/14-148-L.

6. Mirzaie M, Yassini E, Ganji S, Moradi Z, Chiniforush N. A Comparative Study of Enamel Surface Roughness After Bleaching With Diode Laser and Nd: YAG Laser. J Lasers Med Sci. 2016;7(3):197-200. doi: 10.15171/jlms.2016.34.

7. Hosoya N, Honda K, lino F, Arai T. Changes in enamel surface roughness and adhesion of Streptococcus mutans to enamel after vital bleaching. J Dent. 2003;31(8):543-8. doi: 10.1016/s0300-5712(03)00109-x.

8. Gallinari MO, Fagundes TC, da Silva LM, de Almeida Souza MB, Barboza A, et al. A new approach for dental bleaching using violet light with or without the use of whitening gel: study of bleaching effectiveness. Oper Dent. 2019;44(5):521-9. doi: 10.2341/17-257-L.

9. Zanin F. Recent advances in dental bleaching with laser and LEDs. Photomed Laser Surg. 2016;34(4):135-6. doi: 10.1089/pho.2016.4111.

10. Rastelli ANS, Dias HB, Carrera ET, de Barros ACP, dos Santos DDL, Panhóca VH, et al. Violet LED with low concentration carbamide peroxide for dental bleaching: A case report. Photodiagnosis Photodyn Ther. 2018;23:270-2. doi: 10.1016/j.pdpdt.2018.06.021.

11. Brugnera AP, Nammour S, Rodrigues JA, Mayer-Santos E, Freitas PM, Brugnera Junior A, et al. Clinical Evaluation of In-Office Dental Bleaching Using a Violet Light-Emitted Diode. Photobiomodul Photomed Laser Surg. 2020;38(2):98-104. doi: 10.1089/photob.2018.4567.

12. Lima DAN, Aguiar FHB, Liporoni PCS, Munin E, Ambrosano GMB, Lovadino JR. In vitro assessment of the effectiveness of whitening dentifrices for the removal of extrinsic tooth stains. Braz Oral Res. 2008;22(2):106-11. doi: 10.1590/s1806-83242008000200003.

13. Hendricks JL, Marshall TA, Harless JD, Hogan MM, Qian F, Wefel JS. Erosive potentials of brewed teas. Am J Dent. 2013;26(5):278-282.

14. Meurman JH, Ten Cate JM. Pathogenesis and modifying factors of dental erosion. Eur J Oral Sci. 1996;104(2 (Pt 2)):199-206. doi: 10.1111/j.1600-0722.1996.tb00068.x

15. Kury M, Perches $C$, da Silva DP, André CB, Tabchoury CP, Giannini M, et al. Color change, diffusion of hydrogen peroxide, and enamel morphology after in-office bleaching with violet light or nonthermal atmospheric plasma: An in vitro study. J Esthet Restor Dent. 2020;32(1):102-12. doi: $10.1111 /$ jerd. 12556 .

16. Ergin E, Ruya Yazici A, Kalender B, Usumez A, Ertan A, Gorucu J, et al. In vitro comparison of an Er:YAG laser-activated bleaching system with different light-activated bleaching systems for color change, surface roughness, and enamel bond strength. Lasers Med Sci. 2018;33(9):1913-8. doi: 10.1007/s10103-018-2555-0.

17. Buchalla W, Attin T. External bleaching therapy with activation by heat, light or laser - a systematic review. Dent Mater J. 2007;23(5):586-96. doi: 10.1016/j.dental.2006.03.018

18. Mendonça LC, Naves LZ, Garcia L, Correr-Sobrinho L, Soares CJ, Quagliatto PS. Permeability, roughness and topography of enamel afther bleaching: tracking channels of penetration with silver nitrate. Braz J Oral Sci. 2011;10(1):1-6. Doi: 10.20396/bjos.v10i1.8641669.

19. Hauss Monteiro DD, Valentim PT, Elias DC, Moreira AN, Machado Cornacchia TP, et al. Effect of surface treatments on staining and roughness of bleached enamel. Indian J Dent Res. 2019;30(3):393-8. doi: 10.4103/ijdr.IJDR_233_16.

20. Wongpraparatana I, Matangkasombut O, Thanyasrisung P, Panich M. Effect of vital tooth bleaching on surface roughness and streptococcal biofilm formation on direct tooth-colored restorative materials. Oper Dent. 2018;43(1):51-9. doi: 10.2341/16-366-L. 
21. Miranda CB, Pagani C, Benetti AR, Matuda Fda S. Evaluation of the bleached human enamel by Scanning Electron Microscopy. J Appl Oral Sci. 2005;13(2):204-11. doi: 10.1590/s1678-77572005000200021.

22. Pinto CF, Oliveira Rd, Cavalli V, Giannini M. Peroxide bleaching agent effects on enamel surface microhardness, roughness and morphology. Braz Oral Res. 2004;18(4):306-11. doi: 10.1590/s1806-83242004000400006.

23. Ferreira Sda S, Araújo JL, Morhy ON, Tapety CM, Youssef MN, Sobral MA. The effect of fluoride therapies on the morphology of bleached human dental enamel. Microsc Res Tech. 2011;74(6):512-6. doi: 10.1002/jemt.20939.

24. Hegedüs C, Bistey T, Flóra-Nagy E, Keszthelyi G, Jenei A. An atomic force microscopy study on the effect of bleaching agents on enamel surface. J Dent. 1999;27(7):509-15. doi: 10.1016/s0300-5712(99)00006-8.

25. Ushigome T, Takemoto S, Hattori M, Yoshinari M, Kawada E, Oda Y. Influence of peroxide treatment on bovine enamel surface--cross-sectional analysis. Dent Mater J. 2009;28(3):315-23. doi: 10.4012/dmj.28.315.

26. De Abreu DR, Sasaki RT, Amaral FL, Flório FM, Basting RT. Effect of home-use and in-office bleaching agents containing hydrogen peroxide associated with amorphous calcium phosphate on enamel microhardness and surface roughness. J Esthet Restor Dent. 2011;23(3):158-68. doi: 10.1111/j.1708-8240.2010.00394.x.

27. Sa Y, Chen D, Liu Y, Wen W, Xu M, Jiang T, et al. Effects of two in-office bleaching agents with different pH values on enamel surface structure and color: an in situ vs. in vitro study. J Dent. 2012;40 Suppl 1:e26-e34. doi: 10.1016/j.jdent.2012.02.010. 